\title{
I-Voting on Cloud Framework
}

\author{
D.Sathishkumar, M.SureshAnand, J.JeganAmarnath, A.SangeeraniDevi, S.Gurusubramani
}

\begin{abstract}
With large scale automation gathering pace among various branches and services, the paper proposes an Online Voting System built on a Cloud Framework which combines the fairness and privacy of the existing system which uses Electronic Voting Machines, with the transparency and pliability of the new-age technology by using Cloud Computing Framework wherein a community cloud can secure the required biometrics and couple it with the web framework and mobile application to ensure a free-and-fair elections with the voting right at the voters fingertip. This paper proposes a Cloud Framework which can implement this Internet-Voting (I-Voting) by employing Aadhar UIDAI (Unique Identification Authority of India) secured by encryption techniques which can be deployed by a software or an application where the user can validate his biometrics and vote in quick-time, which can then be encrypted and stored in a database from where the results can be accessed quickly saving time and resources. The proposed application combines Cloud Framework, Data Security and Biometric Verification along with what advantages it offers against the existing systems.
\end{abstract}

Index Terms: Internet Voting, Voting, Cloud Computing, Elections in India, Election

\section{INTRODUCTION}

Electronic Voting was introduced in India in the 1990s and was fully inoculated into the election machinery in 2004 and ever since the Electronic Voting has grown by bounds, effectively eliminating any fraudulent methods being used with earlier ballot papers, thus bringing integrity, fairness and secrecy which were required for must in modern-day elections. With the digital revolution in India, E-Voting can take a step ahead with this venturing into the I-Voting and bring the flexibility and robustness of the new-age technology into the whole machinery eliminating much of the manpower and time-consuming process which go hand-in-hand with the election process in India which is subjected to a herculean set-up to ensure a free-and-fair execution.

I-Voting allows any individual who has access to the Internet, either through their Personal Computer/Laptop or Smartphone to cast their vote in a secure manner without any hackles or standing in time-consuming queues. India's internet base already exceeds half a billion people currently using Internet services and applications in day-to-day activities which speak volumes about the Internet

Revised Manuscript Received on October 18, 2019.

D.Sathishkumar, Department of Computer Science Engineering, Sri Sairam Engineering College, Chennai.

M.SureshAnand, Department of Computer Science Engineering, Sri Sairam Engineering College, Chennai.

J.JeganAmarnath, A.SangeeraniDevi, S.Gurusubramani, Department of Computer Science Engineering, Sri Sairam Engineering College, Chennai. penetration in the country. Along with this, about $99 \%$ of India's adults who are eligible to vote is covered by the Aadhar which is the Unique Identification Authority of India and consists of a 12-digit Unique Identification Number of an individual which is drawn out by the biometrics of the individual which includes the finger-print and retina scan. The individual biometrics is secured in a comprehensive security policy in the Aadhar database which can then be drawn with other interfaces to allow any adult who is eligible to vote to securely cast his vote.

Our proposed model is built to address the limitations posed by the current machinery which plagues the Indian Elections resulting in many shortcomings like low voter turnout percentage by infusing a robust framework which can make the whole system viable in scalability and as well as security.

\section{I-VOTING SETUP}

To make the concept of Internet-Voting viable in a new digital world, we have to set up proper infrastructure and framework to satisfy the necessary laid down conditions of securing the privacy of the voter and also to ensure that the voting process is not being conducted in a coerced environment thus fulfilling the conditions of a free and fair elections.

(1) Mobile Application/Computer Software: A mobile application or computer software must be deployed which is freely available and can be downloaded easily by anyone who wishes to partake advantages of I-Voting. The application will perform the role of an interface between the person eligible to vote and the Election Commission who will oversee all the processes going on. The system on which the application is working must be compatible with a biometric sensor like a fingerprint sensor or face detection software which will be able to ascertain the voter and his credentials. (2) District Node: The district node will be deployed in every district of the area where the elections are being conducted and will represent a single node and the data-centre where all the votes which have been put in will be secured and encrypted before storing it into the central database of the electoral rolls of Election Commission.

(3) Cloud Storage of the central database: The electoral rolls of the Election Commission will be stored onto a Cloud which will rely on a Platform-as-a-service to store all the credentials of the voters and their votes which will exclusively accessible only to Election Commission. During the counting procedure, the votes can be accessed directly from the cloud and then computed upon to ascertain the results of the election.

(4) Verification Set-Up: The I-Voting will also employ the use of verification algorithms and 


\section{I-Voting on Cloud Framework}

also detect dubious behaviour from a user. When a new user wants to register for I-Voting, he needs to sign-up using his UIDAI Number which will further proceed with Election Commission officers ascertaining his identity by physical verification. The user will be further prompted for a mail and Phone Number registration.

(5) Vote Verification: For each vote cast, the user will be granted a special token with a unique 12-digit code which he can then use to visit the Election Commission site and ascertain the fact that his vote has been counted and tallied thus ensuring the transparency of the system and also to prevent the vote from being traced by miscreants.

\section{Architecture Set-Up:}

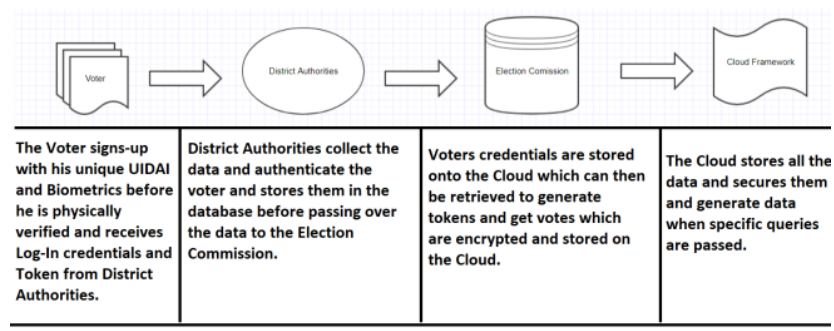

\section{SETTING UP CLOUD COMPUTING}

To develop the I-Voting as a viable means of voting to prevail the existing limitations with the election machinery, we rely on new-age technologies. Cloud Computing is a new-age technology and has seen sufficient growth and development in recent years. The cloud computing models can be deployed as public, private and hybrid depending on the need and can be moulded as per our needs to develop a viable system. For example, Identity as a Service (IDaaS) can be used to authenticate new users and also to verify the votes cast by them in a much more effective manner.

In our proposed model, we will rely on a Cloud with Platform as a Service to secure the Voters credentials and their votes along with other confidential data and will act as a secure interface between the user and the Election Commission and it can sufficiently handle a lot of data flow thanks to its robustness and reliability. The cloud can be accessed only by Election Commission officers to access and switch data while the users can access the cloud only to ascertain that their vote has been validated and stored in the cloud.

\section{EXISTING MODEL}

Indian Elections are one of the most followed events, not only in the political circle of the country, but also in terms of its extent and the scalability associated with it which makes it truly a mega event, which happens every 5 years. Earlier, Indian Elections used to happen with Ballot Papers where each voter will be handed out a ballot after which the voter can mark the candidate whom he wishes to vote for and cast his vote. The system was marred by allegations of manhandling and rampant abuse of this process, especially with politicians exercising unconstitutional powers to influence the election process. This system was completely replaced by the Electronic Voting Machines by 2000s and it accelerated the Indian Voting Machinery to E-Voting.The existing model utilizes an Aadhar Card which houses the
UIDAI which can be verified with the central database and the Election Commission employs an Electronic Voting Machine (EVM) which is secured in a cabin where the voter after identity verification is sent to cast the vote which is then stored in a database. Every polling booth is manned by 4-5 Polling Officers who identify the voters by electoral rolls and after voting the officers are given a figure of the total number of votes cast after which the EVMs are stored away and on the counting day, they are retrieved and then the votes are counted physically. This makes the existing model heavy on costs and manpower which makes it non-effective in our current technological state.

\section{PROPOSED MODEL}

Our proposed model is named as "Internet Voting structured on a Cloud Framework" and it puts to use of novel techniques and technologies in the modern world to deploy an application and framework to allow the concept of I-Voting to a full realization. The I-Voting Framework will comprise of five phases wherein various parties involved in the elections like the Election Commission, district officers and the voters.

(1) Registration Phase: This phase will allow any new user to register for the I-Voting. He simply needs to download an application and sign-up using his UIDAI number and a fingerprint sensor which will ascertain his identity. The user will need to request for a physical verification to activate his account which will be done by Election Commission Officers after which his account will be activated. He will be prompted to register his applications like the Voter Card and educational qualifications (if any) online after which he will receive a mail or an SMS on the E-Mail ID or Phone Number he has registered. This will activate his account.

(2) Voting Phase: On election day, the voter must log in into the I-Voting application which will activate his account and will send a One Time Password (OTP) on his Phone Number or Mail which will allow the cloud to generate a token which can be used to vote. The token will be used to open a secured page which will detail the candidates contesting in the elections where the voter can choose his/her candidate. The voter must have access to his Phone Number and E-Mail ID, during the voting day failing which he would need to apply for a change which will be followed by a verification phase by Election Commission before the request is being processed.

(3) Authentication Phase: The voting phase will be immediately followed by an authentication phase wherein the user would need to enter his thumb impression and a front photo which will be directly sent to the district data-centre to ascertain the voter's identity with the UIDAI database and also to verify if the votes are being cast based upon a person's choice and not under any threat or intimidation. Once the votes are authenticated by specific algorithms, the voter will be sent a token and a confirmation message that his vote has been cast. The token can be used by the voter to access the cloud to ascertain that his/her vote has been cast safely. Authentication Phase can allow the user to ascertain that the vote being cast if their right and no other person, even with access to their UIDAI or

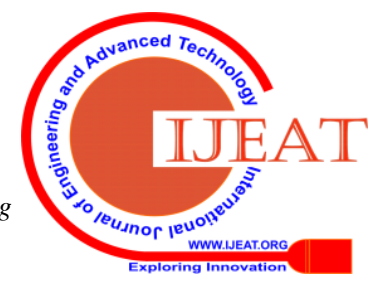


Contact Details can access their right to vote without bypassing the biometric authentication which adds a layer of security to the whole framework.

\section{will}

(4) Storage Phase: On election day, the district data-centers will collect all the votes, and will encrypt it using an attribute based public-key cryptographic technique. The use of cryptographic technique is being implemented to secure the votes and the voter's identity from misuse by unauthorized users who might wish to access such data against official3) purposes. The encryption technique will utilize Advanced Encryption Standard or Data Encryption Standard to secure both the ends of the framework against blatant data misuse and make the system adherent to the policies of security and privacy. Usage of the Cloud framework, the votes can be easily encrypted and uploaded which can then be accessed by the central data-centre for easy counting.

(5) Counting Phase: When the Voting and Storage Phase is up, the Counting Phase will be invoked on the Results day, wherein the data stored in the cloud will be decrypted and displayed for immediate results with algorithms immediately displaying the auto-tallied figures for an immediate result. To perform this operation, specially designed algorithms will be invoked to perform heavy computations on the data sets acquired from the data centers which will be computed to develop trends and calculate the final result of the elections.

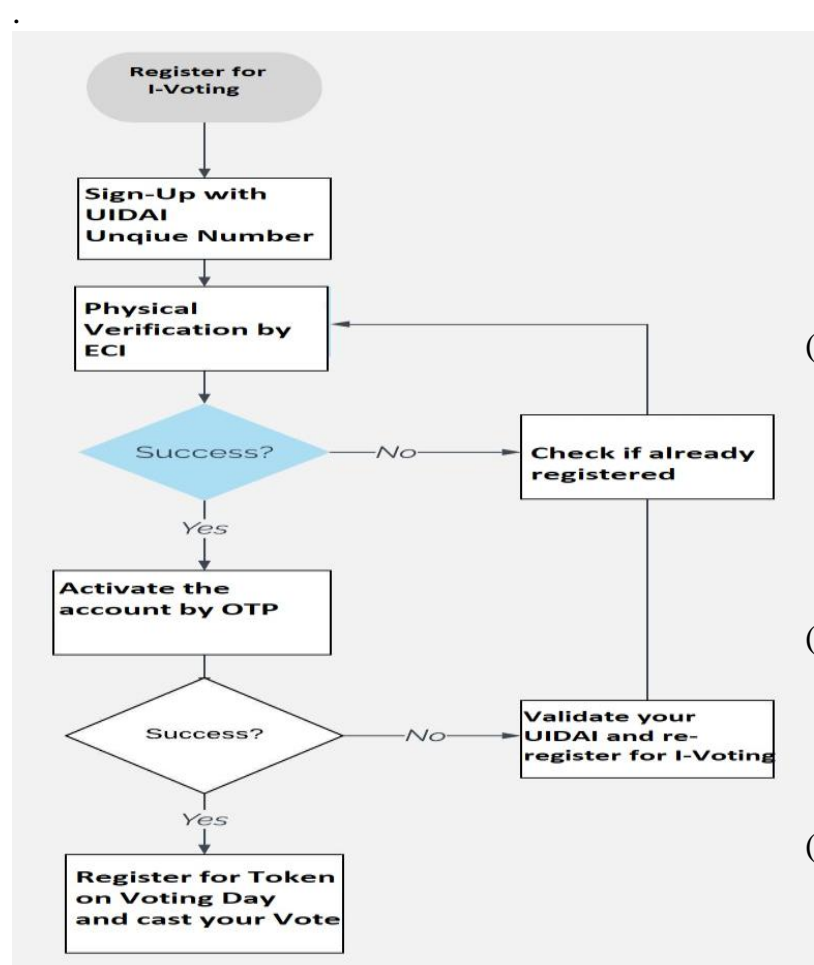

Fig: Flowchart to depict how a voter can cast his vote using an I-Voting Application

\section{ADVANTAGES OVER EXISTING MODEL}

The advantages of our proposed model over the existing one are:

(1) Higher Voting Percentages: This system can enforce higher voting percentages since the voter no longer needs to stand in long queues and can comfortably vote sitting at their home or workplace by employing their device. All they need is a verified account and Internet service to cast their vote.

Low manpower required: National level elections required heavy manpower to be secured and conducted. In 2019, General Elections in India, almost 0.3 million Paramilitary Forces and 2 million Policemen were deployed along with a large number of officers. This can be nullified by the usage of modern novel technologies.

Cloud scalability: The implementation of the current model runs into severe complexities due to a wide number of databases and no absolute back-up. Mishaps can lead to valuable data being lost against no absolute backup which will lead to serious issues. The scalability issues can be redressed by the adoption of a Cloud Framework which will be scalable and also enforce data backup.

(4) Transparency: In the older systems with Ballot Papers and currently with Electronic Voting Machines, the voter cannot ascertain the status of his vote and whether it has been cast to the candidate he has voted for. This cast serious apprehensions about the transparency. Usage of the cloud can further redress this as the user can check on the status of his/her vote once he cast it by using a token which he can then use to login to the Cloud. Such a measure reaffirms a voter's faith on the democracy and the free-fair elections in the nation.

(5) Localization: The I-Voting would allow a voter to cast the vote from anywhere around the country without needing to check into his hometown where his Voter ID card was made. The prime reason for low voter turnout percentage has been the tedious election process which is time and resource consuming which can be prevented by implementing such a measure. This will make the whole election machinery more flexible and will allow people to vote en masse further redressing low voter turnout percentage issues.

(6) Reduced Costs: Implementation of a Cloud Framework with Data Security will further reinforce better efficiency in regards to funds being allocated since the automation process can relieve many Election Commission personnel of their chores during the elections and will further reduce the expenditure being incurred by the Government during the election process.

(7) Managing Data-Sets: Our proposed model can help the Election Commission to better manage the data resources available with it by enforcing computer-models along with Cloud Framework which will further make the whole machinery more efficient in design and implementation.

(8) Privacy: Our proposed model enforces better privacy measures than the vintage frameworks and will secure the voter's identity and confidentiality by implementing web security using biometric authentication and cautious review implemented using Intelligent algorithms and information encryption which will prevent data lapses against cyber threats and malevolent people.

(9) Swift: The implementation of our proposed model can speed up the entire election process from few weeks to just a few hours. Currently the General Elections are conducted in phases across various states. Implementation of a Net-Based framework can allow multiple people across the country to vote at the same time and increase the speed of elections with faster computations being performed boosting the 


\section{I-Voting on Cloud Framework}

technological prowess of the framework.

\section{CONCLUSION}

Our proposed model "Internet Voting structured on a Cloud Framework" can help India, to fulfill the dream of a fair and transparent democracy by bringing more people into the election machinery and giving more freedom to the people to exercise their right to vote with the employment of Cloud Framework to further accelerate the voting operations and the counting phase which will serve the needs of voters and the nation alike. In this paper, we discussed our model and how it can come to fructification in various phases paving way for a new dawn to the Indian Election Set-Up.

\section{REFERENCES}

1. Ramesh, S. and Muralibhaskaran, V. (2019). Internet voting using cloud computing - IET Conference Publication. [online] Ieeexplore.ieee.org. Available at: https://ieeexplore.iee.org/document/6143423 [Accessed 6 Jul. 2019].

2. The Economic Times. (2019). 3 lakh paramilitary, 20 lakh state police personnel deployed in 7-phase LS polls. [online] Available at: https://economictimes.indiatimes.com/news/elections/lok-sabha/india/3lakh-paramilitary-20-lakh-state-police-personnel-deployed-in-7-phase-ls -polls/articleshow/69412844.cms [Accessed 6 Jul. 2019].

3. Ieeexplore.ieee.org. (2019). Voting from the Home or Office? Don't Hold Your Breath - IEEE Journals \& Magazine. [online] Available at: https://ieeexplore.ieee.org/document/4270552/ [Accessed 6 Jul. 2019].

4. Ieeexplore.ieee.org. (2019). The patchwork of internet voting in Canada IEEE Conference Publication. [online] Available at: https://ieeexplore.ieee.org/document/7001134/ [Accessed 6 Jul. 2019].

5. Ieeexplore.ieee.org. (2019). Trustworthy Electronic Voting Using Adjusted Blockchain Technology - IEEE Journals \& Magazine. [online] Available at: https://ieeexplore.iee.org/document/8651451/ [Accessed 6 Jul. 2019].

6. K. Vijayakumar and C. Arun, "A Survey on Assessment of Risks in Cloud Migration”, International Journal of Applied Engineering Research, ISSN 0973-4562 Vol. 10 No.66 May 2015.

7. K. Vijayakumar and C. Arun, "Continuous Security Assessment of Applications in Cloud Environment”, International Journal of Control Theory and Applications, ISSN: 0974-5645 volume No. 9(36), Sep 2016, Page No. 533-541.

8. R.Joseph Manoj, M.D.Anto Praveena, K.Vijayakumar, "An ACO-ANN based feature selection algorithm for big data", Cluster Computing The Journal of Networks, Software Tools and Applications, ISSN: 1386-7857 (Print), 1573-7543 (Online) DOI: 10.1007/s10586-018-2550-z, 2018.

\section{AUTHORS PROFILE}

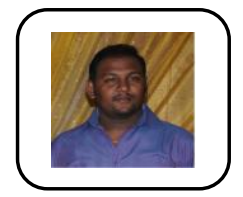

D.Satish Kumar, completed Bachelor degree (B.Tech) in Information Technology from anna University and Masters in Information Technology from Sathyabama University. Working as a Assistant Professor in Sri Sairam Engineering College, Chennai. Area of Research is networking and wireless communction. Life member of CSI, ISTE and IAENG.

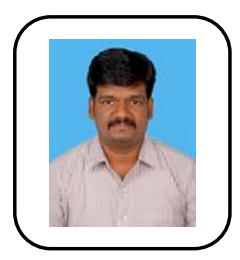

M.SureshAnand, is working as an Associate professor/CSE in Sri Sairam engineering college, Chennai. He had published more than 50 papers in reputed journals and conferences. He is having 15 years of experience in teaching. His areas of interest are Image Processing, Computer Vision, Machine Learning, Human Computer Interaction and Deep Learning. He also member in IAENG \& IACSIT.

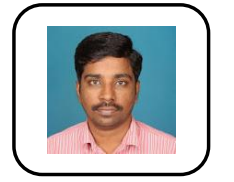

J.JeganAmarnath, is working as an Associate professor/CSE in Sri Sairam engineering college, Chennai. He had published papers in reputed journals and conferences. He is having 20 years of experience in teaching. He is a member in IAENG \& IACSIT. His areas of interest are Data mining, Soft computing, Artificial intelligence, Machine Learning, Human Computer Interaction and Deep Learning.

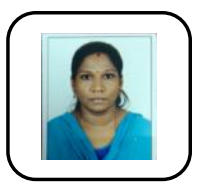

A.Sangeerani Devi B.Tech(IT),M.E(CSE), Assistant Professor, Department of Computer Science and Engineering, Sri Sairam Engineering College having 12+ years of teaching experience. My area of interest is Data Mining and Big Data Analytics. Life Time member of ISTE, CSI, published 3 papers in Indian Journal of Public Health Research \& Development a scopus indexed journal.

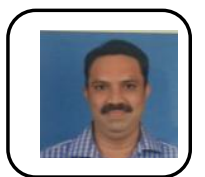

IAENG.
S.Gurusubramani, is working as an Associate professor/CSE in Sri Sairam engineering college, Chennai. $\mathrm{He}$ is having 20 years of experience in teaching. His areas of interest are e-learning, Computer networks, Cloud computing and Distributed systems. He also member in 